\title{
Time-action Studies and Clinical Trial of Actrapid and Crystal II Novo Insulins
}

\author{
B. F. CLARKE,* M.B., M.R.C.P.ED. ; J. F. MUNRO,* M.B., M.R.C.P.ED. ; L. J. P. DUNCAN,* M.B., B.SC., F.R.C.P.ED.
}

Brit. med. F., 1965, 2, 265-267

Two new insulins, Actrapid and Crystal II, have recently been added to the ever-lengthening list of insulin preparations (Schlichtkrull, Munck, and Jersild, 1965). We report a study of their time-actions and the results of a clinical trial in certain diabetics for whom they were thought to be particularly suitable.

\section{The Insulins}

Actrapid is prepared from recrystallized pig insulin and has a $\mathrm{pH}$ of 7 , at which the pig insulin crystals are soluble. It is said to have a more prompt action than soluble insulin, which has to come from $p \mathrm{H} 2.9$ to neutral $p \mathrm{H}$ before achieving biological activity.

Crystal II insulin has the same chemical composition and $p \mathrm{H}$ as Actrapid but is prepared by crystallizing beef insulin. These crystals, unlike those of pig insulin, remain undissolved when the $p \mathrm{H}$ of the suspension is raised to 7 . They are slowly absorbed after subcutaneous injection and have an intermediate time action, the duration of which depends on the

* The Diabetic and Dietetic Department, Royal Infirmary, Edinburgh.

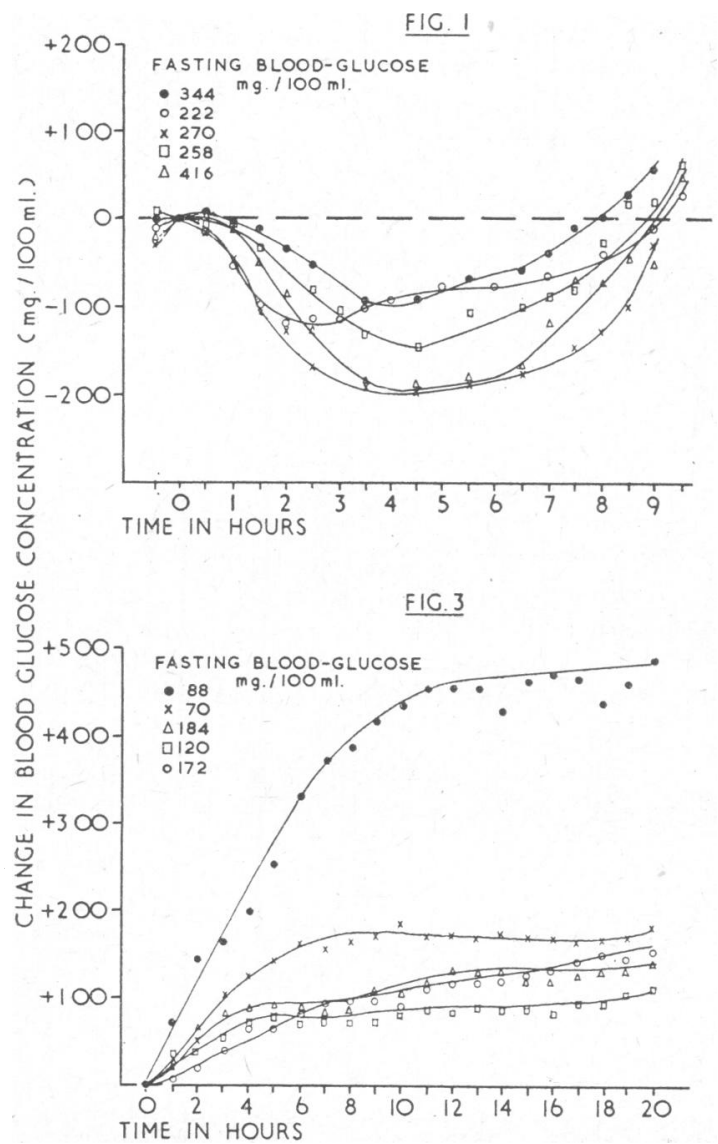

physical properties of the crystals and not on the presence of added zinc or protein.

Actrapid and Crystal II insulins have the advantage that they are completely miscible in all proportions without interaction between the components or loss of their individual times of action.

\section{Studies of Time-action}

The times of action of these insulins were assessed in well-controlled, insulin-dependent adult male diabetics who were admitted to hospital for the period of study. They were given only soluble insulin on the day preceding the test, they fasted overnight, and the blood-glucose level was obtained the following morning. The insulin being tested was then injected subcutaneously and the patient given $15 \mathrm{~g}$. of carbohydrate by mouth as a fluid feed; similar feeds were subsequently taken at hourly intervals throughout the test period. Venous blood samples were withdrawn at 30 - or 60 -minute intervals thereafter for blood-glucose determination, using the Technicon AutoAnalyzer.

Each of five patients was given Actrapid and soluble insulin on different days so that their times of action could be assessed

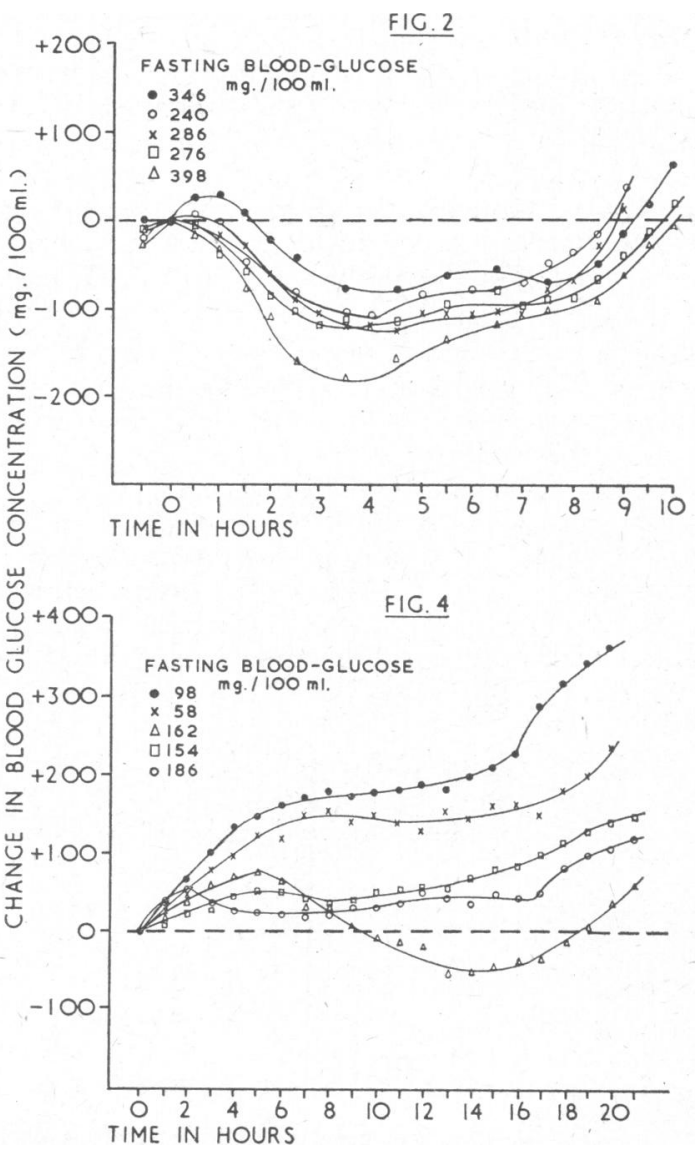
Fig. 1.-Time-action of Actrapid insulin in five patients. Fig. 2.- Time-action of soluble insulin in the same five patients
as in Fig. 1. FIG. 3.-Blood-glucose values in five patients given carbohydrate feeds and no insulin, as described in text. FIG. 4.-Blood-glucose values in the same five patients as in Fig. 3 given Crystal II insulin as described in text. 
and compared. The fasting blood-glucose levels were high enough to preclude the development of hypoglycaemia during the test, and in each patient the two fasting levels did not vary by more than $20 \mathrm{mg}$. $/ 100 \mathrm{ml}$. The dose of insulin given each patient was the same as his usual morning dose of soluble. Actrapid insulin was effective within 30 minutes and continued to have a major action for five and a half hours with diminishing influence until approximately eight hours (Fig. 1). Soluble insulin also acted within 30 minutes, but its major effect lasted for seven and a half hours (Fig. 2).

The time-action of Crystal II insulin was determined in five other subjects and compared with a placebo injection of isotonic salne, the initial blood-glucose levels being comparable for each patient. The dose of Crystal II insulin given was twothirds the patient's usual dose of protamine zinc insulin. In all subjects Crystal II insulin exerted a definite effect within three hours, with the major action occurring from 6 to 15 hours, wearing off rapidly by 18 hours (Figs. 3 and 4).

\section{Selection of Patients and Conduct of Clinical Trial}

Ten adult insulin-dependent out-patients were selected (see Table). All were taking protamine zinc insulin and soluble insulin, injected separately through the same needle before breakfast, and soluble insulin before the main evening meal. They were well instructed in the principles of diabetic selfregulation (Dunlop and Duncan, 1964) and appreciated the necessity for emptying the bladder half to one hour before passing the urine specimen to be tested. Control was considered unsatisfactory, because, despite appropriate alterations of the carbohydrate content of the various meals or in the insulin dosage, either (1) the urines before the main evening meal continued to show 1-2\% glycosuria, although the pre-lunch tests were generally glucose-free (Cases 1-4 and 6-10), or (2) attempts to reduce persistent $1-2 \%$ glycosuria in the beforebreakfast samples resulted in night-time hypoglycaemia (Cases 5-10). Some patients (Cases 6-10) presented both these problems. During the two to four weeks before changeover, patients kept a daily record of their activities, urine test results, and insulin dosage. They were then instructed to inject Actrapid and Crystal II mixed in the same syringe twice daily, before breakfast and before the main evening meal, and to continue their record of activities, urine test results, and insulin dosage.

The initial doses of morning and evening Actrapid insulin chosen were slightly less than the corresponding doses of soluble insulin, and the doses of morning and evening Crystal II insulin were respectively about two-thirds and one-third of that of protamine zinc insulin. Subsequent adjustments were made by the patients according to the results of the appropriate urine tests; frequent blood-glucose estimations were not obtained, since urine tests provided the patient with the information required for his day-to-day diabetic self-regulation. Thus alteration in the doses of the morning Actrapid and Crystal II insulins were based on the urine tests before lunch and before the main evening meal respectively; and in those of the evening Actrapid and Crystal II insulins on the tests before bed-that is, just before the late evening snack-and before breakfast. The day was regarded as being divided into four periods-morning, afternoon, evening, and night-each of which corresponded to the time of major action of one of the four insulins, although the time-action studies had demonstrated a definite overlap of effect (Fig. 5).

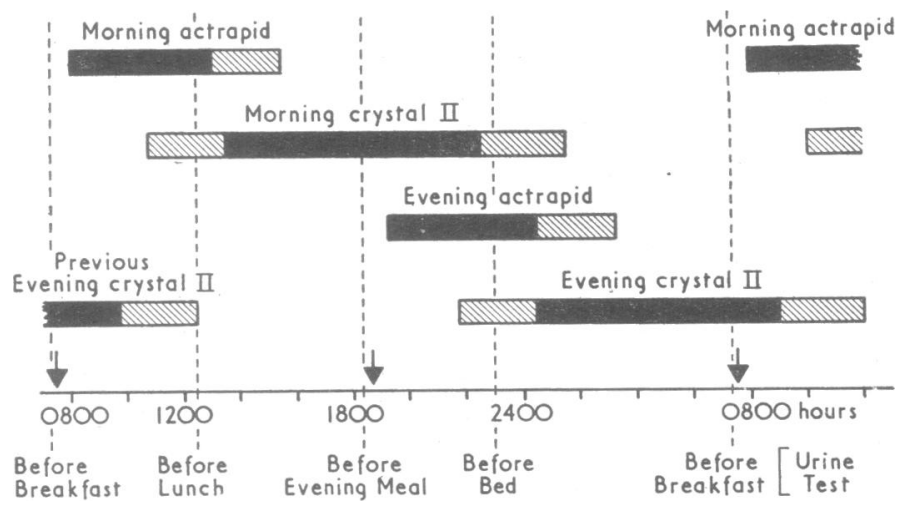

FIG. 5.-Times of action of the individual insulins-hatched areas indicate increasing and decreasing action, and shaded areas show maximal effect. Times of injection indicated by arrows.

\section{Results}

Satisfactory control with the new regime was usually established in two to three weeks; during this period no severe hypoglycaemic reactions or significant ketonuria occurred. The insulin requirement thereafter remained fairly constant except when alterations were deliberately made to allow for increased activity or during periods of intercurrent infection and other stress. The Table shows the total daily dose of the crystal insulins and of the protamine and soluble insulins.

All patients were studied for more than one year and some for as long as two years. All succeeded in reducing the late afternoon and/or morning glycosuria (see Table) and experienced no difficulty in adjusting their insulins according to the test results.

Local sensitivity to the insulins was not observed.

\section{Discussion}

The best possible diabetic regulation is required for patients likely to live long enough to develop specific diabetic complications, since good control may reduce this risk. The purpose of treatment is to provide adequate carbohydrate in the diet and ensure its maximum utilization by giving enough insulin to prevent undue hyperglycaemia and consequent glycosuria. Although it is impossible to abolish postprandial glycosuria without inducing hypoglycaemic reactions, glycosuria before

Average Urine Test Results of the 10 Patients During the Two Regimens of Treatment. Dosage of Insulin in International Units.

Urine Test Results Expressed as \% Glycosuria as Determined by Clinitest-Results 1, 2, 3, and 4 are those Obtained in Tests Done Before Breakfast, the Main Midday, the Main Evening, and the Pre-bed Meals Respectively

\begin{tabular}{|c|c|c|c|c|c|c|c|c|c|c|c|c|c|c|c|c|c|}
\hline \multirow{3}{*}{ No. } & \multirow{3}{*}{$\begin{array}{l}\text { Sex } \\
\text { and } \\
\text { Age }\end{array}$} & \multirow{3}{*}{$\begin{array}{c}\text { Duration } \\
\text { of } \\
\text { Diabetes } \\
\text { (yrs) }\end{array}$} & \multicolumn{7}{|c|}{ Treatment with Soluble and P.Z.I. } & \multicolumn{8}{|c|}{ Treatment with Crystal Insulins } \\
\hline & & & \multicolumn{2}{|c|}{ Morning } & \multirow{2}{*}{$\mid \frac{\text { Evening }}{\text { Sol. }}$} & \multicolumn{4}{|c|}{ Urine Test Results } & \multicolumn{2}{|c|}{ Morning } & \multicolumn{2}{|c|}{ Evening } & \multicolumn{4}{|c|}{ Urine Test Results } \\
\hline & & & Sol. & P.Z.I. & & 1 & 2 & 3 & 4 & AR & CII & $\mathrm{AR}$ & CII & 1 & 2 & 3 & 4 \\
\hline $\begin{array}{r}1 \\
2 \\
3 \\
4 \\
5 \\
6 \\
7 \\
8 \\
9 \\
10\end{array}$ & $\begin{array}{cc}F & 55 \\
M & 43 \\
M & 31 \\
M & 32 \\
M & 40 \\
M & 26 \\
M & 32 \\
M & 22 \\
M & 46 \\
F & 24\end{array}$ & $\begin{array}{r}3 \\
6 \\
3 \\
5 \\
20 \\
4 \\
18 \\
15 \\
20 \\
12\end{array}$ & $\begin{array}{l}8 \\
36 \\
20 \\
12 \\
28 \\
20 \\
20 \\
52 \\
16 \\
10\end{array}$ & $\begin{array}{l}28 \\
44 \\
8 \\
44 \\
28 \\
56 \\
60 \\
48 \\
44 \\
36\end{array}$ & $\begin{array}{l}8 \\
20 \\
12 \\
12 \\
16 \\
24 \\
48 . \\
12 \\
10\end{array}$ & $\begin{array}{l}0-\frac{1}{1} \\
0-\frac{1}{1} \\
0-\frac{1}{1} \\
0-\frac{1}{2} \\
1-2 \\
1-2 \\
1-2 \\
\frac{1}{2}-2 \\
1-2 \\
\frac{1}{2}-2\end{array}$ & $\begin{array}{c}0-\frac{1}{4} \\
0 \\
0 \\
0-\frac{1}{4} \\
0 \\
0 \\
0-\frac{1}{4} \\
0-\frac{1}{4} \\
0 \\
0-\frac{1}{4}\end{array}$ & $\begin{array}{c}1-2 \\
\frac{1}{2}-2 \\
1-2 \\
2 \\
0-\frac{1}{4} \\
1-2 \\
1-2 \\
1-2 \\
2 \\
1-2\end{array}$ & $\begin{array}{l}0-\frac{1}{1} \\
0-\frac{1}{1} \\
0-\frac{1}{1} \\
0-\frac{1}{2} \\
0 \\
0-\frac{1}{1} \\
0-\frac{1}{1} \\
0-\frac{1}{1} \\
0-\frac{1}{2} \\
0-\frac{1}{1}\end{array}$ & $\begin{array}{r}4 \\
12 \\
12 \\
4 \\
4 \\
4 \\
6 \\
56 \\
8 \\
6\end{array}$ & $\begin{array}{l}14 \\
64 \\
52 \\
68 \\
20 \\
28 \\
44 \\
32 \\
40 \\
24\end{array}$ & $\begin{array}{r}12 \\
12 \\
6 \\
4 \\
4 \\
4 \\
6 \\
48 \\
8 \\
4\end{array}$ & $\begin{array}{r}10 \\
8 \\
20 \\
18 \\
20 \\
34 \\
44 \\
28 \\
14 \\
10\end{array}$ & $\begin{array}{c}0-\frac{1}{4} \\
0-\frac{1}{4} \\
0 \\
0 \\
0-\frac{1}{4} \\
0 \\
0 \\
0-\frac{1}{4} \\
0-\frac{1}{2} \\
0\end{array}$ & $\begin{array}{c}0-\frac{1}{1} \\
0-\frac{1}{4} \\
0 \\
0-\frac{1}{4} \\
0-\frac{1}{4} \\
0 \\
0 \\
0-\frac{1}{2} \\
0-\frac{2}{2} \\
0\end{array}$ & $\begin{array}{c}0-\frac{1}{4} \\
0-\frac{1}{2} \\
0 \\
0 \\
0 \\
0-\frac{3}{4} \\
0 \\
0-\frac{1}{4} \\
0-\frac{1}{4} \\
0-\frac{3}{4}\end{array}$ & $\begin{array}{c}0-\frac{1}{4} \\
0-\frac{1}{4} \\
0-\frac{1}{2} \\
0 \\
0 \\
0-\frac{1}{4} \\
0 \\
0-\frac{1}{4} \\
0-\frac{1}{4} \\
0-1\end{array}$ \\
\hline
\end{tabular}


meals can be minimized by the use of that insulin or combination of insulins best suited to the patient. In our experience nearly all of the so-called difficult diabetics can be satisfactorily controlled by soluble insulin and protamine zinc insulin in the morning and soluble insulin in the evening, provided they understand and put into practice the principles of diabetic self-regulation (Dunlop and Duncan, 1964). In some patients this proves impossible for several reasons, of which two are mentioned above; although these could have been overcome by using other insulins-for example, soluble and globin insulins given twice daily-the crystal insulins seemed to be suitable and had the advantage of being miscible in the same syringe.

The results show that in these circumstances the insulins were satisfactory and that the major action of each insulin was correctly reflected by the selected urine test on which its dosage was based. The dose of Actrapid, however, was usually much less than that of Crystal II insulin because of the overlapping effect of the previously injected Crystal II. Nevertheless the patients readily appreciated that during each of the four periods of the day (morning, afternoon, evening, and night) one insulin was having its greatest effect, and had no difficulty in making the necessary adjustments in dosage or diet to allow for flexibility in their physical activity and meals. This regime would seem to be suitable for the limited number of diabetics who are not well controlled on more conventional insulin regimes.

A mixture of Actrapid and Crystal II insulins is now available as Rapitard (Lopez and Colombo, 1964 ; Schlichtkrull et al.,
1965). This mixing of the two insulins in predetermined proportions is in our view most regrettable, since it deprives them of their only advantage, which is the appropriate adjustment of their individual dosage by the patient.

\section{Summary}

Time-action studies of Actrapid and Crystal II insulins are reported. Actrapid insulin has a short action comparable to soluble insulin, and Crystal II insulin has an intermediate time-action.

The method and results of their use over a period of one to two years are described in a group of 10 patients whose control was previously judged as unsatisfactory.

We are indebted to Drs. K. Hallas-Moller and J. Schlichtkrull, of the Novo Terapeutisk Laboratories, Copenhagen, and to Dr. G. A. Carnachan, of Evans Medical Ltd., Liverpool, for generous supplies of Actrapid and Crystal II insulins; to Professor L. G. Whitby, of the Department of Clinical Chemistry, for the bloodglucose estimations ; and to Miss $\mathrm{O}$. Jehu, dietitian, and the nursing staff for valuable assistance with the time-action studies.

\section{REFERENCES}

Dunlop, Sir Derrick, and Duncan, L. J. P. (1964). In Textbook of Medical Treatment, edited by Sir Derrick Dunlop, Sir Stanley Davidson, and S. Alstead, 9th ed., pp. 341-357. Livingstone, Edinburgh. Lopez, V., and Colombo, J. P. (1964). Schweiz. med.' Wschr., 94, 788. Schlichtkrull, J., Munck, O., and Jersild, M. (1965). Acta med. scand., 177, 103 .

\title{
An Improved Method of Transporting Donor Eyes
}

\author{
F. O. MUELLER,* M.D., D.O. ; P. O'NEILL,* B.SC. ; P. D. TREVOR-ROPER,* M.D., F.R.C.s., D.o.M.s.
}

Brit. med. F., 1965, 2, 267-270

In 1922 Filatov reported that corneas from cadavers formed satisfactory homografts. It has since been shown that for a successful graft of the full corneal thickness the donor eye should be removed within 10 to 15 hours after death, and should be stored for not longer than three days (Rycroft, 1962).

The establishment of the Westminster-Moorfields Eye Bank has allowed a reassessment of some of the methods devised for short-term storage and transport of these donor eyes. In this paper we present some of our findings and describe new equipment for the transport of eyes.

\section{Materials and Methods}

After preliminary trials with various transport-containers we chose a metal box (known as " box A"), which appears to be that in most general use in England, and which represents the prototype of other transport-containers available. This was used as a basis for comparison with " box B," made of foamed polystyrene, which we have designed in an attempt to find a container that is more economical, lighter in weight, and, in particular, one that achieved better temperature-control.

Box A (Fig. 1) consists essentially of two metal boxes, one within the other, the intervening space being filled with fibreglass. Two specimen jars are fixed in the centre of the container by a screw-clamp, and ice is packed around them. The

\footnotetext{
* From the Department of Ophthalmology, Westminster Hospital,
London.
}

metal lid, of a similar structure as the container, is rubber-lined, and is clamped down on the container to make it watertight. The dimensions of the box are 9 in. $\left(22.8 \mathrm{~cm}\right.$.) long, $6 \frac{1}{2} \mathrm{in}$. $(16.5 \mathrm{~cm}$.) wide, 6 in. $(15.2 \mathrm{~cm}$.) high; its weight is $3.3 \mathrm{~kg}$. when empty; and the volume of the ice compartment is 1.37 litres.

Box B (Fig. 2) is made of foamed polystyrene. A large central cavity holds the ice in a plastic bag, and communicates

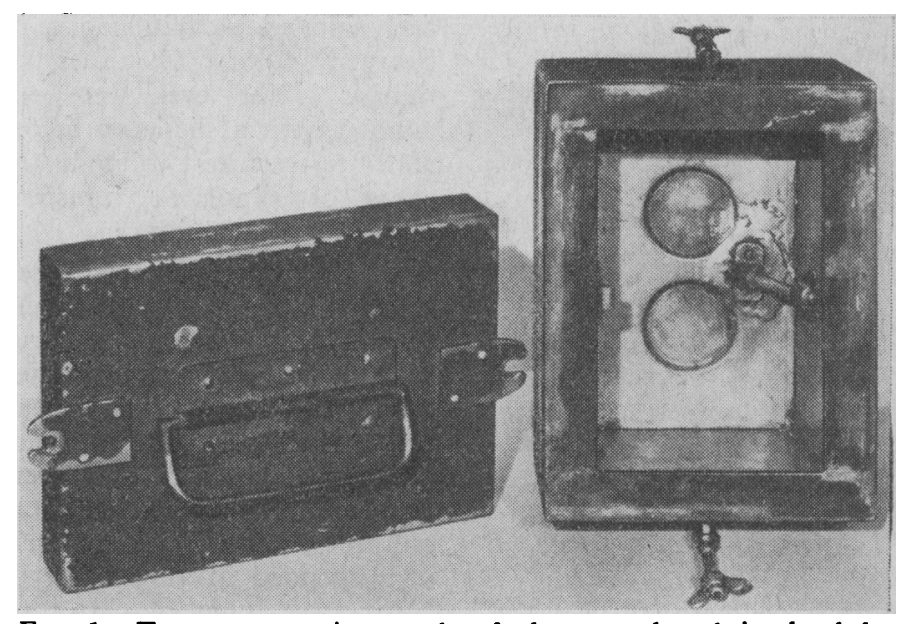

Fig. 1.- Transport container made of sheet metal and insulated by fibreglass-box A. 